\title{
Polarization Jet: characteristics and a model
}

\author{
Y. I. Galperin ${ }^{\dagger}$ \\ ${ }^{1}$ Space Research Institute, 84/32 Profsoyuznaya Str., Moscow, 117997, Russia \\ $\dagger$ passed away on the 28 December 2001
}

Received: 21 February 2001 - Revised: 15 June 2001 - Accepted: 2 July 2001

\begin{abstract}
Recent analysis of the ground-based observations of the Polarization Jet (PJ) effects in the subauroral ionosphere has shown that PJ can rapidly develop in the nearmidnight sector near the Harang Discontinuity (HD). Based on these observations, a simple, semi-quantitative theory of the PJ formation and its main characteristics is constructed. According to the model, PJ starts to develop, as proposed by Southwood and Wolf, 1978, due to the penetration of the injected energetic ions to the deeper L-shells in the presence of the westward component of the electric field. The injection near the tip of the HD is assumed here. The initial development stage of the PJ band, considered only qualitatively, is supposed to lead to its inclination inward toward evening with respect to the lines $B=$ const. Within the model proposed, the PJ band, once formed, will be sustained by the continuous charging at its equatorial side, at first, mainly by the newly injected ring current ions, and later by the plasma sheet ions convected inward through the HD. In addition, an important charging of the PJ band occurs at its polar side by energetic electrons drifting eastward. These electrons were either previously on the trapped orbits or convected inward from the plasma sheet, and encounter the PJ polar border. The model semi-quantitatively describes the main features of the PJ events: the typical cross-PJ voltage drop $(\sim 10 \mathrm{kV})$, the resulting double-sheet current loop feeding the PJ, the recently observed short PJ formation time near midnight ( $\sim 10$ min or less) accompanied by a fast westward HD displacement, the nearly steady-state PJ location in the evening to midnight MLT sector and width in the ionospheric frame, the bell-shape of the electric field latitude profile, and the long PJ lifetime (up to several hours) - all are in rough accord with observations. Further developments of the model now in progress are briefly described.
\end{abstract}

Key words. Magnetospheric physics (electric fields; magnetosphere-ionosphere interactions; storms and substorms)

\section{Introduction}

Polarization Jet $(\mathrm{PJ})$ is a spectacular substorm phenomenon at subauroral latitudes - a supersonic narrow stream of

Correspondence to: L. Zelenyi (lzelenyi@iki.rssi.ru) plasma at, or near, the equatorward convection boundary (Galperin et al., 1973, 1974; Smiddy et al., 1977). Its morphology and statistical characteristics were studied both from satellites (see, Spiro et al., 1979; Maynard et al., 1980; Vondrak and Rich, 1982; Anderson et al., 1991, 1993; Bankov et al., 1996; Karlsson et al., 1998; Burke et al., 1998, 2000), and from ground-based observations (see, Unwin and Cummack, 1980; Sivtseva et al., 1984; Galperin et al., 1986; Filippov et al., 1989; Providakes et al., 1989; Yeh et al., 1991). Generally, PJ was considered to occur during substorm recovery phase (Spiro et al., 1979; Anderson et al., 1991, 1993; Karlsson et al., 1998).

However, recent analysis by Khalipov et al. (2001) of extensive ground-based observations at $L=3$ during more than 20 years, led to the conclusion that in the near-midnight MLT sector, PJ can appear within no more than $\sim 10 \mathrm{~min}$ after an important $A E$-index burst ( $>500 \mathrm{nT}$ ). These observations were made at the Yakutsk station (geographic latitude $62^{\circ} \mathrm{N}$, longitude $129.8^{\circ} \mathrm{E} ; \mathrm{MLT}=\mathrm{UT}+9 \mathrm{~h} ; L=3.05$ ) using both the specific PJ signature on vertical and oblique subauroral ionograms (see Sivtseva et al., 1984; Galperin et al., 1986; Filippov et al., 1989) and, when observable, the accompanying weak SAR arc from optical auroral measurements (see, Ievenko, 1993; Alexeev et al., 1994). At the same time the average PJ delay from the substorm onset for all the ground-based data sets amounts to $\sim 30 \mathrm{~min}$ in the nearmidnight sector and increases towards evening MLT hours, reaching $\sim 1-2 \mathrm{~h}$. These average delays are in rough accord with the statistics accumulated from the satellite crossings of PJ by Spiro et al. (1979) and Karlsson et al. (1998). It may be noted that several cases of similar short delays $(<10 \mathrm{~min}$ in the $\sim 21-22$ MLT sector) were indeed shown by Karlsson et al. (1998) from the FREJA data (see their Fig. 9). Delays of $10 \mathrm{~min}$ of echoes were also noted by Unwin and Cummack (1980) in the VHF radar observations, and simultaneous magnetic field variations were observed from the region of the developing PJ at $L=4.1$, indicating westward extension of the negative electrojet. These short delays sometimes found the presence a new constraint for the PJ generation schemes.

Several theoretical and model studies were performed of the PJ (or, SAID - SubAuroral Ion Drift, as it is sometimes called after the paper by Spiro et al., 1979). The basic idea of the physical explanation of PJ was put forward by South- 
wood and Wolf (1978). It was the penetration of the injected drifting energetic ions to lower latitudes (or, $L$-shells) due to conservation of the first two adiabatic invariants, in the presence of the dawn-dusk electric field component along the ion drift trajectory. The resulting positive charging at the equatorial ion drift trajectories leads to the poleward electric field. The validity of this idea was demonstrated by the Rice Convection Model calculations (Spiro et al., 1981), where such a band of the poleward electric field was well reproduced at the equatorial edge of the ion penetration after an injection. Banks and Yasuhara (1978) noted that the rapid electric field drift within the PJ band leads to a large increase in the effective recombination coefficient in the F- and E-regions of the ionosphere, and to a resulting strong depletion of the electron density within the PJ band. This depletion is accompanied, and enhanced, by a fast westward transport of the plasma flux tubes, and by the associated plasma heating and field-aligned ion motions (see, for example, a review of model calculations of ionospheric plasma effects in a PJ band by Roger et al., 1992, and also other model calculations by Korosmesey et al., 1992; Moffett et al., 1998; Grigoriev et al., 1999). These active processes in the subauroral ionosphere lead to a significant modification of the plasma characteristics all along the PJ band and at altitudes until the equatorial plane. It was shown that a PJ can cause a notable depletion even at the plasmaspheric altitudes (Ober et al., 1997).

The contemporary theoretical concepts on the PJ origin and evolution were discussed by Providakes et al. (1989); Anderson et al. (1993) and recently by Karlsson et al. (1998) and Burke et al. (2000). Other interesting ideas and models on the PJ origin were discussed by Deminov and Shubin (1987; 1988), where effects of a slow equatorward motion of the PJ were considered. Recently, De Keyser et al. (1998), and De Keyser (1999) analyzed the PJ as a rotational discontinuity and considered the finite Larmor radius effects to define the PJ width and cross- $L$ velocity. However, the early appearance of at least some of the PJ events during the substorm expansion phase (when observed in their sector of origin) makes the time scale of the PJ generation too short for some of these models. In another set of studies, such an energetic ion penetration to lower $L$-shells after a substorm injection was shown to lead to the formation of the "nose structures" of energetic ions by Chen (1970); Konradi et al. (1975); Kaye and Kivelson (1981) (see also Ganushkina et al., 2000 for another approach to the modeling of the "nose structures"). However, neither the simultaneous motions of the energetic electrons, nor the time scale of the discharge of the injected charges through the conducting ionosphere was considered, and possible relations between the PJ and the "nose structures" were not analyzed.

Recently, a very detailed case study of the injection of the hot ions and electrons to these subauroral $L$-shells was performed from the CRRES satellite measurements at $4.5 \leq$ $L \leq 5.5$, together with the data from three geosynchronous satellites in the night sector (Sergeev et al., 1998). It was shown that a sharp front with a bipolar magnetic variation (negative then positive, $\sim \pm 15-20 \%$ in the $B_{Z}$ component, see their Fig. 7) passed the satellite at $L \sim 5$ moving with the convection velocity in $\sim 8 \mathrm{~min}$ from the geostationary orbit. The "injection" was manifested by a sharp intensity increase both for ions in the range $\geq 100 \mathrm{keV}$ and for electrons in the range $\geq 20 \mathrm{keV}$. In addition, quite convincing model results based on the data from several satellites indicate an intensity increase also at lower energies, at least for electrons. The MLT range of this injection was evaluated as $\sim 2.5-3 \mathrm{~h}$ MLT in the premidnight sector. This case study documents for the first time in detail a substorm "injection" to subauroral latitudes, and its results can be used in future modeling of these injections.

Below, using first principles and order of magnitude estimates, we construct a simplified theory and model for the PJ band origin, its driving potential drop and cross-PJ current, its width and lifetime. The model, despite its simplicity, describes semi-quantitatively the main PJ band characteristics. More elaborate model calculations based on this idea, with a more detailed account of particle spectra, geometry, etc., are deferred to a later paper.

\section{The model basis}

\subsection{Ionospheric Pedersen conductivity and current}

To evaluate the ability of a mechanism to sustain the PJ band during its lifetime of $\geq 100 \mathrm{~min}$, we need some crude estimates of the electric circuit parameters involved.

From the observations it is known that the $\Delta \Phi_{\mathrm{PJ}}$, the potential difference across the PJ, of a width of $\sim 100 \mathrm{~km}$ can be about $10 \mathrm{kV}$, while the FAC density is at most $\sim 1 \mu \mathrm{A} / \mathrm{m}^{2}$ (Rich et al., 1980). Observed values during substorms according to Karlsson et al. (1998) are up to $\Delta \Phi_{\mathrm{PJ}} \sim 10 \mathrm{kV}$, but can be $30 \mathrm{kV}$ during a large storm (see, Burke et al., 2000). As for the Pedersen conductivity profile across the band, its evaluation is not straightforward because the band usually (or always) exists in both conjugate ionospheres, one (or both) of which can be sunlit. According to the satellite measurements, the respective $\Delta \Phi_{\mathrm{PJ}}$ values in the conjugate ionospheres across the PJ band are comparable (Anderson et al., 1991; Karlsson et al., 1998; Burke et al., 2000). A double-sheet current loop must develop along the PJ band, with its downward current at the equatorial side and upward current at the polar side. Evidently, this weak downward current is carried by the upward streaming ionospheric electrons to compensate for the positive charges created near the equatorial plane by the injected energetic ions. At the polar edge of a PJ, the charge carriers of the weak upward current can be both hot electrons of the inner plasma sheet (or, the diffuse auroral zone), scattered into the loss-cone, and ionospheric ions moving upward.

Assume the total width of the downward current at the equatorial edge of the PJ band as $d_{1}=10^{4} \mathrm{~m}$, its current density $j_{\|}=10^{-6} \mathrm{~A} / \mathrm{m}^{-2}$, the width of the PJ band $d=10^{5} \mathrm{~m}$, and the potential drop across it $\Delta \Phi_{\mathrm{PJ}}=10 \mathrm{kV}$. The line current density across the PJ is then $J_{\perp \Sigma}=d_{1} \cdot j_{\|}=10^{-2} \mathrm{~A} / \mathrm{m}$. 
After the PJ is set up, the integrated Pedersen conductivity $\Sigma_{P}$ for both ionospheres across the PJ band, i.e. $\Sigma_{P}=$ $\left(1 / \Sigma_{P N}+1 / \Sigma_{P S}\right)^{-1}$ according to Banks and Yasuhara (1978), drops quickly and reaches a rather low value. It can be evaluated to the order of magnitude from the relation

$\Sigma_{P}=J_{\perp \epsilon} \frac{d}{\Delta \Phi_{\mathrm{PJ}}}$.

Supposing the voltage generator at the equatorial plane (Burke et al., 2000), and a significant asymmetry in the solar zenith angle at the conjugate ionospheres, and, hence, also in the Pedersen conductivity, we drop the indices $S, N$ and rely primarily on the sunlit ionosphere. Substituting the model values for the $J_{\perp \Sigma}, \Delta \Phi_{\mathrm{PJ}}$ and $d$, we come from Eq. (1) to the estimate $\Sigma_{P}=0.1 \mathrm{~S}$, which is not inconsistent with the ionospheric data available. (These values are not too far from those adopted in the model by Karlsson et al. (1998) from other considerations where $J_{\perp \Sigma}=0.5 \cdot 10^{-2} \mathrm{~A} / \mathrm{m}$; $\left.0.2<\Sigma_{P}<0.02 S\right)$. With such a low conductivity even a modest steady inflow of positive charges of the energetic ions to the equatorial side of the PJ can sustain the observed high values of the $\Delta \Phi_{\mathrm{PJ}}$.

Assuming the length $l$ of the PJ band at ionosphere at $L=4$ of at least $3 \mathrm{~h} \mathrm{MLT}$, or $l=\left(2 \pi R_{E} \cdot \cos 60^{\circ}\right) / 8 \sim$ $2250 \mathrm{~km}$, the total line current across the two conjugate PJ bands $J_{\perp \Sigma \Sigma}=J_{\perp \Sigma} \cdot l$ will be of the order of $J_{\perp \Sigma \Sigma}=$ $2.25 \cdot 10^{4} \mathrm{~A}=2.25 \cdot 10^{23} \mathrm{ions} / \mathrm{s}$.

\subsection{Particle source to sustain the cross-PJ current}

The current $J_{\perp \Sigma \Sigma}$ allows one to evaluate approximately the total number of the charges which must be provided by the equatorial voltage generator per second during the PJ lifetime. During the lifetime of a PJ band $\tau_{p} \sim 2 \mathrm{~h} \sim 7.2 \cdot 10^{3} \mathrm{~s}$, there must be $N_{\Sigma}=J_{\perp \Sigma \Sigma} \cdot \tau_{P} \sim 1.62 \cdot 10^{27}$ energetic particles injected at $L \sim 4$ to sustain a PJ band. Evidently, they must be provided by some form of particle injection - either more or less continuous or as a burst. Let us evaluate these two possibilities.

Recently, Rowlands and Wygant (1998) and Wygant et al. (1998) have shown, by using the CRRES electric field measurements, that strong large-scale electric fields of $\sim$ $1 \mathrm{mV} / \mathrm{m}$, quasi-stationary but fluctuating, can exist in the equatorial inner magnetosphere at $K_{P} \geq 3$. Their generally westward direction can provide the necessary inward drift of energetic particles from the tail all along the nightside of the PJ band location with the betatron acceleration to the energies of the electrons and ions of the order of, or more than, the "resonance" energy $E r \sim 30-40 \mathrm{keV}$ explained below (see Sect. 3).

To demonstrate the ability of this large-scale and long duration type of an inflow (or a persistent injection) to sustain the average cross-PJ current flow, the following estimate can be made. The mapping factor along the length of the PJ band to the dipole equator is $L^{3 / 2}$. Assuming the value for the number density of the energetic particles, $N_{h} \sim 3 \cdot 10^{6} \mathrm{~m}^{-3}$ and the long-term westward electric field of $E_{W}^{e q} \sim 1 \mathrm{mV} / \mathrm{m}$ taken from Rowlands and Wygant, 1998, the inflow of the betatron accelerated particles at the equator from the tail is

$I=N_{h} \cdot V_{\perp E} \cdot l \cdot L^{3 / 2}$,

where for the dipole field at the equator at $L=4$, the electric field drift velocity is $V_{\perp E}=2.05 \cdot 10^{3} \mathrm{~m} / \mathrm{s}, l=4 R_{E}=$ $2.55 \cdot 10^{7} \mathrm{~m}, L^{3 / 2}=8$. An important part of this inflow at the polar edge of the PJ band supposedly transforms to the downward current (in both conjugate ionospheres) and then to the resulting two cross-PJ line currents. The evaluated maximal line current density in the ionosphere across $\mathrm{PJ}$ in one hemisphere from Eq. (2) appears to be $J_{\perp} \sim 0.1 \mathrm{~A} / \mathrm{m}$. This value is consistent with the cross-PJ total current $J_{\perp \Sigma}=10^{-1} \mathrm{~A} / \mathrm{m}$ estimated above.

Thus, a persistent influx of hot ions from the tail across the PJ can sustain the cross-PJ Pedersen current within the observational constraints during a disturbed time. It may be noted that the betatron acceleration in a dipole field from the geostationary orbit $L=6.6$ to $L=4$ and $L=3$ amounts to the energy gain of 4.5 and 10.6 times, respectively. So the typical plasmasheet ions of 3-10 keV, with their betatron acceleration up to the energies $E \sim 30-40 \mathrm{keV}$, drifting to these inner magnetosphere $L$-shells, obtain quite enough perpendicular energy to sustain the PJ and "nose structure" during their lifetime.

By comparison, the ability of a short-term energetic particle injection burst at, say, $L=4$, to be the source of the PJ and of the "nose structure" of energetic ions of $\sim 30 \mathrm{keV}$ energy during their lifetime can also be tested against the above constraint. The first question is to obtain the $N_{\Sigma} \sim 1.10 \cdot 10^{27}$ hot ions from a single equatorial injection, within the nearequatorial region of the feasible volume $C \sim\left(2 \cdot R_{E}\right)^{3}=$ $2.1 \cdot 10^{21} \mathrm{~m}^{3}$. With the same number density of hot ions of $N_{h}=3 \cdot 10^{6} \mathrm{~m}^{-3}$, we obtain $N_{\Sigma}^{*}=N_{h} \cdot C=6.3 \cdot 10^{27}$. So to produce the needed amount of ions, $\sim 15 \%$ of the injected hot ions must be heated to tens of $\mathrm{keV}$. If the injection proceeds as described by Sergeev et al. (1998), the hot plasma convected to $L=4$ from the geosynchronous orbit is adiabatically accelerated, and the needed amount of hot ions is available at the initial stage of the PJ and "nose structure" formation.

However, in the scenario of burst injection, two difficulties can be noted. First, it will lead to an important and sharp magnetic effect in the $D_{s t}$-variation which hardly could go unnoticed. Second, a large, time-of-flight dispersion in energy of the injected ions must be quite notable and will affect the time evolution of the PJ and "nose structure". It may be noted in this regard that in the model calculations of Ejiri et al. (1980), a continuous particle source with the duration of many hours of time was assumed in order to reach good agreement with the observed form of the "nose structure". Thus, a short-term injection to these low $L$-shells can initiate a PJ and a "nose structure", but apparently, it is inadequate to sustain the observed form of these structures for a long enough time compatible with their typical characteristics.

Observations indicate that a burst of injection is needed for the start of the PJ and the "nose structure". But it fol- 
lows from the above comparisons that further in time some long-term mechanism of supply of energetic particles at subauroral $L$-shells, i.e. within the outer belt, may be at work to sustain both their intensity and structure.

\subsection{Quasi-trapped particle motions within the PJ band}

It is well-known that during increased activity, the equipotentials in the evening side come closer to the Earth than in the near-midnight region (see, Galperin et al., 1975; Nopper and Carovillano, 1978). We elaborate on this by assuming that the equatorial projection of the PJ band is slightly inclined to the isolines $B^{e q}=$ const so that it is located at higher $B$ values (lower $L$-shells) for the evening local times than at midnight.

The location of the supposed Substorm Injection (SI) region in the equatorial plane, and the formation region of the resulting PJ band are shown schematically in Fig. 1a. The projection to the subauroral ionosphere of this region (note a highly exaggerated inward displacement!) with superimposed energetic ion drift trajectories is sketched in Fig. $1 \mathrm{~b}$.

From conservation of the particle's full energy, $\epsilon_{0}$, we have

$\epsilon_{0}=e \Phi_{0}+\mu B_{0}=e \Phi+\mu B=e \Phi+\epsilon_{\perp}$,

where $B$ is magnetic field, $e, \epsilon_{\perp}$ and $\mu$ are the particle's charge, perpendicular energy and magnetic moment $(\mu=$ $\left.\epsilon_{\perp} / B\right), \Phi$ is the electric potential, and index 0 is for some arbitrary initial point on the particle trajectory. Let this point be chosen at the particle's entry at the PJ band boundary.

To demonstrate its effects qualitatively, assume the electric field is zero outside the band. The particle drift trajectories at the equatorial plane are calculated in the evening-midnight MLT sector with the coordinates $L$ and $\lambda=\Theta \cdot L$ (where $\Theta=$ (MLT -18$) / 24 \mathrm{~h}$ from the standard equations; McIlwain, 1972):

$$
\begin{gathered}
\frac{d L}{d t}=\frac{1}{B L}\left(\left.\mu \frac{\partial B}{\partial \lambda}\right|_{L}+\left.\frac{\partial \Phi}{\partial \lambda}\right|_{L}\right) \\
\frac{d \lambda}{d t}=-\frac{1}{B L}\left(\left.\mu \frac{\partial B}{\partial L}\right|_{\lambda}+\left.\frac{\partial \Phi}{\partial L}\right|_{\lambda}\right) .
\end{gathered}
$$

Assuming suitable stationary models for $B^{e q}(L, \lambda)$ and for $E^{e q}(L, \lambda)$, the particle trajectories and drift velocities can be calculated starting from the source, or backward from the satellite.

Consider now the equatorial particle whose trajectory enters the PJ band projection to the equatorial plane from its border: the equatorial border for ions or the polar one for electrons. The values of $\epsilon_{\perp}, \Phi$ and $B$ within the PJ band equatorial projection will have index $m$. From Eq. (3), the betatron acceleration occurs:

$\epsilon_{\perp m}-\epsilon_{0}=e\left(\Phi_{0}-\Phi_{m}\right)=e \cdot \Delta \Phi_{m}$,

i.e. the particle increases (or loses) its perpendicular kinetic energy $\epsilon_{\perp}$ to the amount of the change in the electric potential crossed due to its magnetic gradient/curvature drift. (For simplicity we consider here only the equatorial particles for
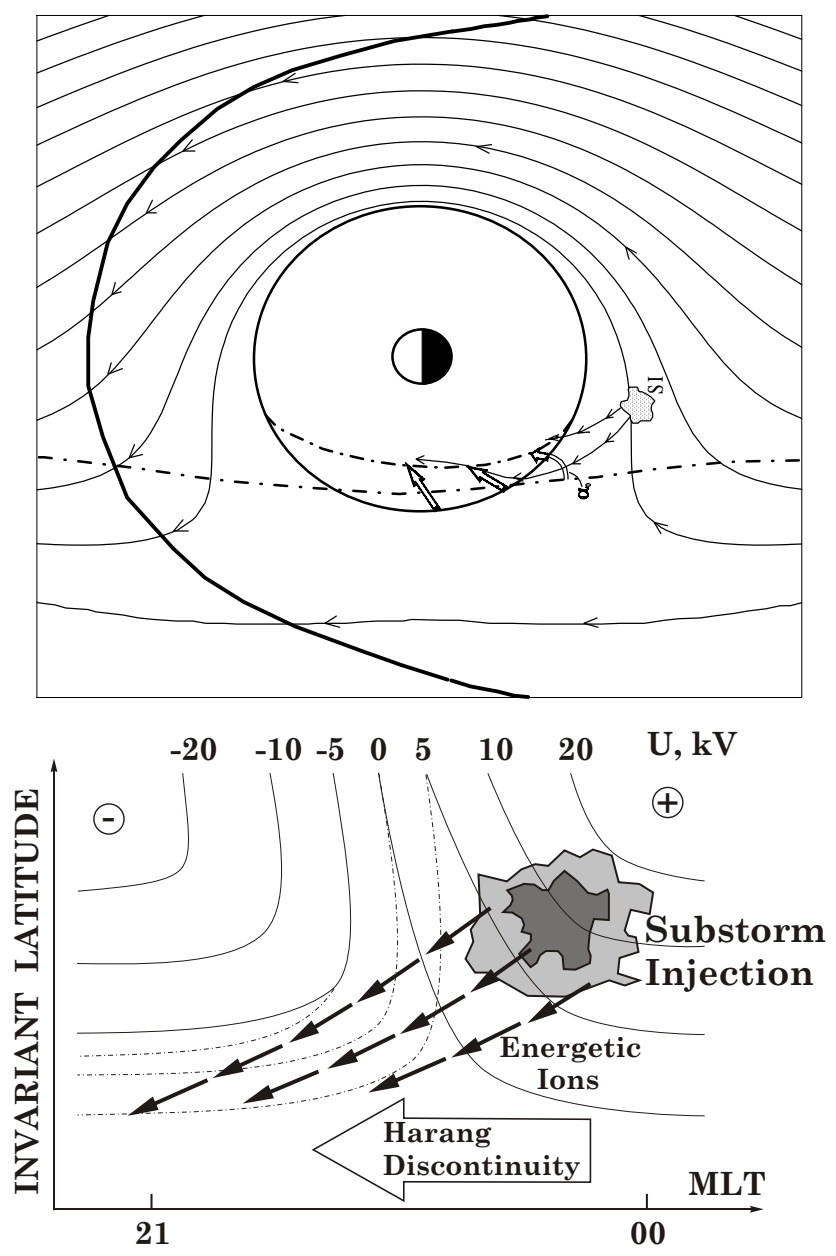

Fig. 1. Schematics of particle injection location, distortion of the Volland-Stern convection pattern at subauroral latitudes, and trajectories of injected energetic ions forming the Polarization Jet (not to scale). Thin lines - equipotentials before the injection, dot-dashed lines - after the injection. Hollow arrows show the inward and westward shift of the equipotential line in the evening sector, lines with arrows - trajectories of the drifting ions penetrating to lower $L$ shells (not to scale). (a) At the equatorial plane; (b) At ionospheric altitudes.

which $\epsilon_{\perp}=\epsilon-$ the kinetic energy). From Eq. (3), a formula can be derived for the dipole magnetic field relating the displacement from $L_{0}$ of a particle of the initial energy $\epsilon_{0}$ to the new $L$-shell, $L_{m}$, and the potential difference $\Delta \Phi_{m}$ crossed (for $\epsilon_{\perp 0} \neq 0$ ):

$\frac{L_{m}}{L_{0}}=\left(1+\frac{e \cdot \Delta \Phi_{m}}{\epsilon_{0}}\right)^{-1 / 3}$

which does not depend on the drift velocity $V_{\perp}^{e q}$, and, hence, on the drift time. (If $\epsilon_{\perp} 0=0$, then $\Delta \Phi_{m}=0 ; L=L_{0}$, and no change of energy or $L$-shell occurs).

This leads to a selection of the range of particle energies for which the modification of the particle energy and, hence, of the dispersive drift motion, is significant during a PJ crossing. Let $\tau_{P}$ be the time duration of the PJ band crossing 
Table 1. "Resonance" ion energies er for different PJ convection velocities $V_{E}^{i}: V_{\nabla B}^{e q}\left(E_{r}\right)=V_{E}^{i} \cdot L^{3 / 2}$

\begin{tabular}{ccc}
\hline$V_{E}, \mathrm{~km} / \mathrm{s}$ & $\epsilon_{r}, \mathrm{keV}$ & $\epsilon_{r}, \mathrm{keV}$ \\
\hline & $L=3$ & $L=4$ \\
1 & $\sim 43.7$ & $\sim 32.8$ \\
2 & $\sim 87.5$ & $\sim 65.5$ \\
4 & 174.9 & 131.0 \\
\hline
\end{tabular}

due to the westward convection electric field component $E_{w}$, i.e. when the full potential difference $\Delta \Phi_{\mathrm{PJ}}$ is crossed. The low energy particles will nearly follow the equipotentials as their gradient drift velocity is low. Their energy gain due to crossing equipotentials will accumulate slowly, so for the time $t \ll \tau_{P}$ they will still be concentrated near their border of origin. For the high energy ones $\epsilon_{0} \gg e \cdot \Delta \Phi$, a relative change in energy is small, as it is, at most, equal to the cross-PJ potential difference $\Delta \Phi_{\mathrm{PJ}}$. Thus, there is a broad "resonance" energy range, $\epsilon_{0} \sim \epsilon_{r}$, for which the relative effect $\Delta \epsilon / \epsilon_{0}$ is most significant during the time $t \leq \tau_{P}$. The particles of these energies, if abundant in the injection, due to the dispersion within the PJ band, will be most effective in the charging process during the time $\sim \tau_{P}$. In the model we assume that $t$ is much longer than the initial phase of the PJ formation $(\sim 5-10 \mathrm{~min})$, say, $\tau_{P} \sim 100 \mathrm{~min}$ in rough accord with observations. This determines the convection velocity across the band, given its width, and, hence, the value $E_{W}$.

Consider now the westward electric drift velocity $V_{\perp E}^{I}$ at the ionosphere within the projection of the PJ band. As is known (Galperin et al., 1974; Spiro et al., 1979; Karlsson et al., 1998), the typical values of the $V_{\perp E}^{I}$ at the ionosphere are from 1 to $3 \mathrm{~km} / \mathrm{s}$, and sometimes even $4 \mathrm{~km} / \mathrm{s}$ or more. (The lower limit of $1 \mathrm{~km} / \mathrm{s}$ was imposed artificially to define the $\mathrm{PJ}$ as the supersonic flow to discriminate possible effects due to strong neutral winds induced by a substorm. Evidently, velocities $V_{\perp E}^{I}<1 \mathrm{~km} / \mathrm{s}$ are also observed, but such events were excluded from the statistics).

Table 1 shows the particle energies at $L=3$ and $L=4$ whose gradient drift velocity at the equator corresponds to the PJ convection drift velocities at the ionosphere. It is seen that these energies fall in the range of typical particle energies of the Ring Current ions at these inner magnetosphere $L$-shells. The resulting modification in particle motion proceeds quite differently for electrons and for ions. For the energetic ions, the westward direction of the electric field drift within the PJ band is the same as for their gradient/curvature drift. For electrons, these drifts are in the opposite directions; so the total drift velocity can have any sign depending on the values of $\epsilon_{0}, L_{0}$ and $E_{W}$.

In Fig. 2, the schematics of the energetic particle drift velocities due to convection $V_{c}$ and to gradient drift $V_{g r}$ within the PJ band equatorial projection in a narrow range of the MLT somewhere near MLT $=21 \mathrm{~h}$ is shown in the rectangular form. (It will be used further in the simplified model described in Sect. 3). For some particular "resonance" energy

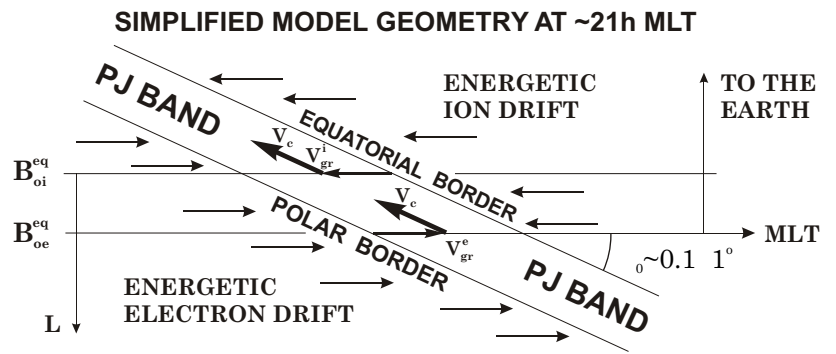

Fig. 2. Schematics of the equatorial projection of the Polarization Jet band inclined to lines $B^{e q}=$ const at a small angle $\alpha_{0}$ (not to scale). Arrows within the band show gradient drift velocity for ions, $V_{g r}^{i}$ (westward), and for electrons, $V_{g r}^{e}$ (eastward), and the common westward convection velocity $V_{C}$. Due to their gradient drift, energetic ions enter the band through its equatorial border, while electrons - through the polar one.

$\epsilon_{r}$, the total zonal electron drift velocity can be zero. This means a slowing down of the electron azimuthal drift motion in the ionospheric frame, or even a reversal of the electron drift motion westward for lower energies. This slowing down is essential for the negative charging of the polar border (see Sect. 3)

\section{Estimate of the steady-state electric field}

A check of the above logic of the charging can be made assuming the resulting configuration of two charged sheets at the edges of the PJ band. If the thickness of the charged sheets in the radial direction is much smaller than the distance between the sheets, it can be considered as a condenser with infinite plates. Then the average surface charge density $\sigma$ of a thin sheet per unit length of the band can be evaluated by integrating along the magnetic field from the ionosphere to equator from

$\int \sigma d l=\frac{J_{\perp \Sigma}}{V_{\|}}$,

where $J_{\perp \Sigma}$ is the linear current density at the ionosphere, and $V_{\|}$is the field-aligned current velocity. To estimate a maximum value of $V_{\|}$, remember that the ionospheric Pedersen current is carried by ions, and their maximal velocity is about their thermal velocity, so let $V_{\|}=1 \mathrm{~km} / \mathrm{s}$. Taking, as before, $J_{\perp \Sigma}=10^{-2} \mathrm{~A} / \mathrm{m}, l=4 \cdot R_{E}$, we arrive at an estimate of the charge density at one border $\sigma=J_{\perp \Sigma} /\left(V_{\|} \cdot l\right)=$ $4 \cdot 10^{-13} \mathrm{C} \mathrm{m}^{-2}$. Then the electric field at the ionosphere generated by one border is $E_{P J}^{i}=\sigma /\left(2 \cdot \epsilon_{0}\right)=0.225 \mathrm{~V} / \mathrm{m}$. This would correspond to the PJ convection velocity of $\sim 4.5 \mathrm{~km} / \mathrm{s}$. So it is a maximal estimate of the electric field for a PJ, which is not inconsistent with the data. 
$\mathrm{F}=\mu \cdot \exp \left(-\mu / \mu_{0}\right) ; \mathrm{E}_{\text {eq }}=5.22 \mathrm{mV} / \mathrm{m} ; \alpha_{0}=0.2 \mathrm{deg} ; \mathrm{L}_{0}=3.5 ; \mu_{0}$ in $\mathrm{keV} / \mathrm{B}_{\text {eq }}$
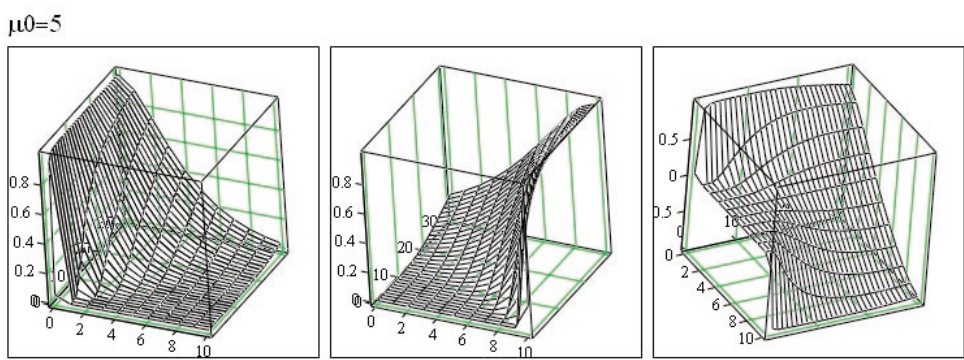

$\mu 0=10$
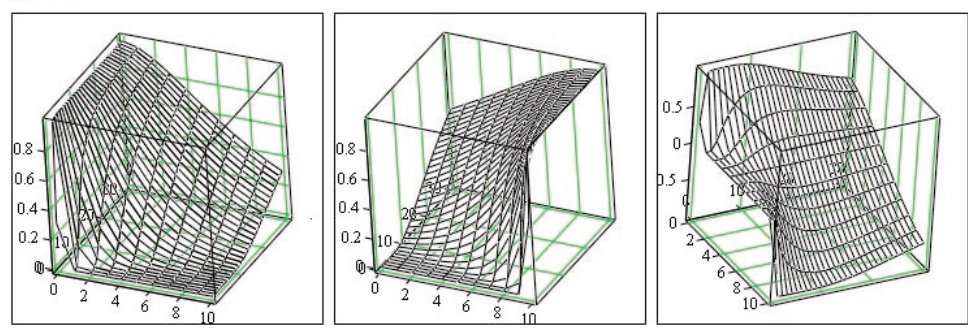

$\mu 0=20$
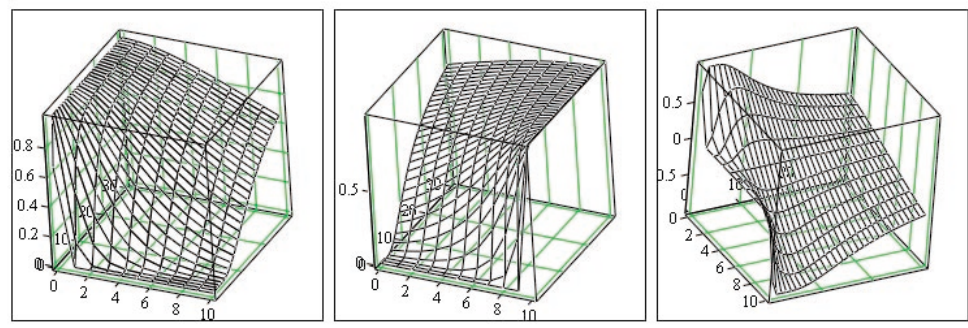

$\mu 0=40$

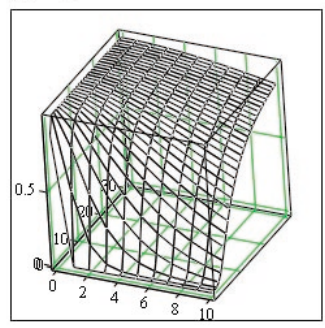

$\mathrm{Ni}$
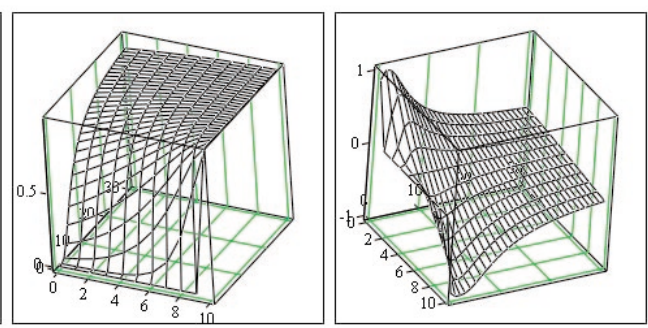

$\mathrm{Ne}$

Nro
Fig. 3. Modelled space-time evolution of the injected particles normalized density of ions $N_{i}$ (left column) and electrons $N_{e}$, (central column), and the resulting normalized charge density $N_{r 0}=N_{i}-N_{e}$, (right column). They are presented as functions of the crossPJ distance $\ell$ at the equatorial plane (in units of $R_{E}$, from 0 to 0.3 at $L \sim$ 3.7 ), and the time $j$ in units of $0.1 \mathrm{~h}$ (i.e. from 0 to $3 \mathrm{~h}$ ) after the start of the quasi-steady stage of the PJ band. The rows are for 4 distribution functions with $\mu_{0}=5,10,20$ and $40 \mathrm{keV} / B^{e q}$, respectively.

\section{A simplified model for injected particle distribution and charging within the $\mathbf{P J}$ band in a steady state}

To illustrate the proposed idea of the particle dispersion mechanism of the PJ formation, the following schematic model in the equatorial plane is assumed. A piece of the PJ projection to the equatorial plane is considered as a rectangular band inclined at the angle $\alpha_{0} \sim 0.01$ radians to the isolines of the magnetic field $B^{e q}=$ const which are assumed to be straight (horizontal in Fig. 2). Their values $B^{e q}=M L^{-3}$ are of the Earth's dipole near $L=3.7$. The electric field $E_{P J}^{e q}$ outside the PJ band projection is assumed to be zero, while within the band $E_{P J}^{e q}$ is constant, perpendicular to the band, and equal to $E_{P J}^{e q}=10 \mathrm{kV} /\left(0.3 \cdot R_{E}\right)=5.22 \mathrm{mV} / \mathrm{m}$. (This approximately corresponds to the westward velocity $1 \mathrm{~km} / \mathrm{s}$ at the ionosphere at $L=3.7$ ). Its westward component is
$E_{W}^{e q}=-\sin \alpha_{0} \cdot E_{P J}^{e q} ; \alpha_{0}=0.2^{\circ}$. Particles are injected constantly at the borders of the PJ band projection to the equatorial plane: ions at the equatorial border, and electrons at the polar one, along a much wider MLT range than the region shown, located somewhere from 18 to 24 MLT. Particle energies are in the range of $\mathrm{keV}$ to tens of $\mathrm{keV}$, taking into account the studies of injection events at the geostationary orbit by Birn et al. (1997a, b; 1998), and deeper in the subauroral magnetosphere by Sergeev et al. (1998).

The westward component of the electric field in this model, drives the gradient-drifting energetic particles inward across the $L$-shells within the PJ band with the velocity

$\frac{d L}{d t}=\frac{E_{W}^{e q} L^{3} n_{1}}{M}<0$, 
where

$n_{1}=1000 \mathrm{~km} / \mathrm{s}[\mathrm{nT} / \mathrm{mV} / \mathrm{m}]=0.1568 \Delta L / s[\mathrm{nT} / \mathrm{mV} / \mathrm{m}]$

and $M=31100 \mathrm{nT}$ is the magnetic moment of the Earth. Upon integration, we obtain the time dependence of $L$ for any particle within the band that entered it at $L_{0}$ at time $t_{0}$ :

$L=\left(L_{0}^{-2}+\frac{2 \cdot E_{W}^{e q} \cdot n_{1}}{M}\left(t-t_{0}\right)\right)^{-1 / 2}$

where $L_{0}$ is at their point of entry on the respective boundary of the PJ, and $t_{0}$ is the time when the quasi-steady PJ has formed $\left(t_{0}\right.$ is not more than $10 \mathrm{~min}$ after the burst injection, see Sect. 4).

In the frame inclined at the angle $\alpha_{0}$ to the lines $B^{e q}=$ const, the electric field has only the component perpendicular to the band, the $E_{P J}^{e q}$, so the respective drift velocity $V_{C}$ is westward along the band, while the magnetic gradient drift velocity $\boldsymbol{V}_{g r}$ is along the lines $B^{e q}=$ const. The total drift velocity $\boldsymbol{V}_{\Sigma}$ for protons is inclined at the angle $\alpha$ to the band borders,

$\sin \alpha=\frac{\left|\boldsymbol{V}_{g r} \sin \alpha_{0}\right|}{\left|\boldsymbol{V}_{g r} \cos \alpha_{0}+\boldsymbol{V}_{\boldsymbol{C}}\right|}$,

where $V_{g r}=n_{1} q \mu L^{-1}, V_{C}=n_{2} E_{P J}^{e q} L^{3}, B=M L^{-3}$, $\mu$ in $\mathrm{keV} / \mathrm{nT}, q=-1$ for ions (westward drift) and +1 for electrons (eastward drift). $E_{P J}^{e q}$ is the radial electric field within the PJ band projection to the equatorial plane; $E_{P J}^{e q}=E_{P J}^{i} K(L)$, where $E_{P J}^{i}$ is its total ionospheric value within the PJ band, $K(L)=L^{-3 / 2} \sqrt{4 L-4 / 4 L-3}$. Since the angle $\alpha_{0}$ is very small, the component perpendicular to the PJ band is $E_{\perp P J}=E_{P J}^{e q} \cdot \cos \alpha_{0} \approx E_{P J}^{e q}$. The angle $\alpha$ somewhat changes due to the betatron acceleration of the particle as it moves across PJ.

We assume that the energetic particles enter the boundaries along a much longer range of $\lambda$ (or MLT), than the region of PJ under consideration here.

For ions, the energy range of particles that have reached a particular distance $\ell$ from the border of origin is limited by the minimum value $\mu_{\min }$ for the ions entering eastward from this meridian, and moving westward and equatorward. We assume that the eastward border of the ion penetration in the band is the HD, which is not too far from midnight but far enough from the region modelled here.

For electrons, the westward convection drift dominates for energies less than $\epsilon_{r}$ (see Table 1), while for higher energies, the total drift is eastward. The results from CRRES described above suggest that electrons convect inward along a wide MLT range. So their MLT range of entry in the band through its polar border is supposed to be both westward and eastward from the region modelled here. Evidently, electrons of all energies convect equatorward across the band according to Eqs. (6) and (8).

As was mentioned above, the dispersion mechanism of the PJ formation described here depends on the energy of injected particles. For illustration purposes, the distribution function for ions (protons) and electrons was assumed in the form

$F(\mu)=A \mu \exp \left(-\mu / \mu_{0}\right)$

which will allow one to see the dependence of the modelled $\mathrm{PJ}$ lifetime on the mean energy of injected particles (which is close to $\mu_{0}$ ), where $A$ is the normalization coefficient, making the total density equal to unity both for injected ions and electrons. We assume that the background plasma density before the injection is much lower and therefore, may be neglected in the charging process described. The value of $\mu_{\mathrm{min}}$, reaching a distance $\ell$ from the border of origin (at which $L=L_{0}=$ const is assumed) depends on $E_{W}^{e q}$, on the elapsed time $t-t_{0}$ after the border crossing, and on $L_{0}$. Then the normalized ion and electron charge densities $N_{i}$ and $N_{e}$ may be evaluated from

$$
N_{i}\left(\ell, t, \mu_{0 i}\right)=\int_{\mu_{i \min (\ell, t)}}^{\infty} F\left(\mu, \mu_{0 i}\right) d \mu
$$

and

$$
N_{e}\left(\ell, t, \mu_{0 e}\right)=\int_{\mu_{e \min (\ell, t)}}^{\infty} F\left(\mu, \mu_{0 e}\right) d \mu .
$$

The quantity $N_{r 0}=N_{i}-N_{e}$ is supposed to be proportional to the surface charge density $\sigma$, so in arbitrary units the equatorial electric field across the band is

$E^{e q}(\ell)=\int_{0}^{\ell} N_{r 0} d \ell$,

and the electric potential

$U^{e q}(\ell)=U_{0} \int_{0}^{\ell}\left[-E^{e q}(\ell)\right] d \ell-U_{00}$.

We neglect a small field-aligned potential difference which may be present and assume $U_{00}=0$.

Model calculations were performed of the normalized energetic ion and electron density $N_{i}, N_{e}$ and of the $N_{r 0}$ per unit length of the band at the equatorial plane as a function of the distance $\ell=L_{i}$ across the band. The width of the equatorial band projection was taken as $0.3 \cdot R_{E}$ at $L \cong 3.7$, which roughly corresponds to the width of the PJ band $\sim 100 \mathrm{~km}$ at the ionosphere.

The time evolution of the cross-PJ profiles $(\ell$-coordinate from 0 to 0.3$)$ of $N_{i}\left(\ell, t-t_{0}\right), N_{e}\left(\ell, t-t_{0}\right)$, and $N_{r 0}\left(\ell, t-t_{0}\right)$ is shown in Fig. 3 for $t-t_{0}=j \cdot 6$ (in minutes) from 0 to $180 \mathrm{~min}$ and for 4 distribution functions (11) with, respectively, $\mu_{0}=5,10,20$ and $40 \mathrm{keV} / B^{e q}$ (4 rows), where $B^{e q}$ is taken at the respective border of entry. It is assumed that the injection intensity at both borders is constant in time and in MLT, both for ions and for electrons, and their distribution functions and the $\mu_{0}$ values are the same. In Figs. $4 \mathrm{a}-\mathrm{d}$, the 

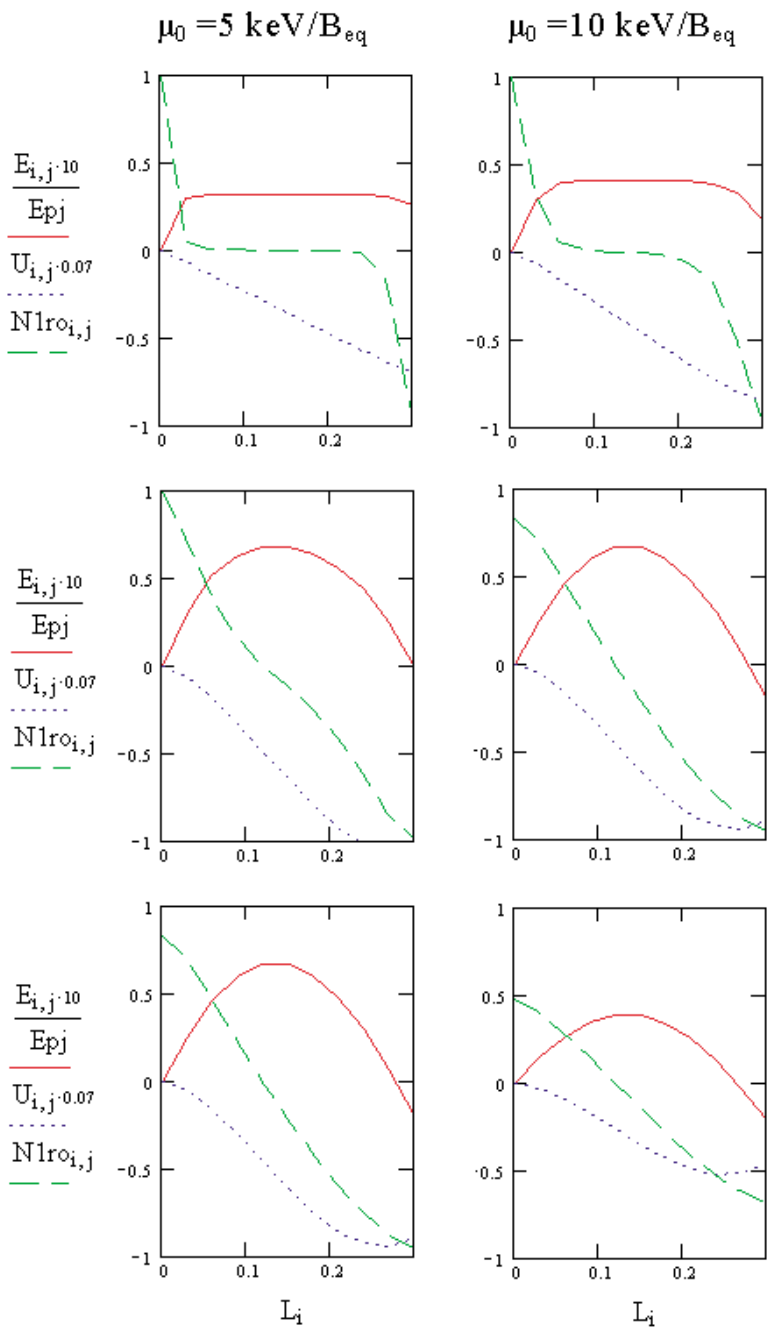

$$
\mu_{0}=10 \mathrm{keV} / \mathrm{B}_{\text {eq }}
$$

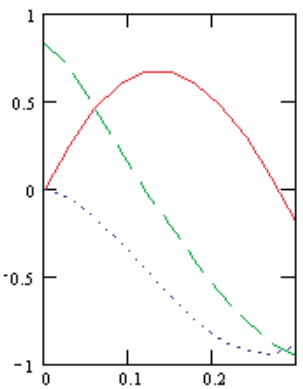

$\mu_{0}=20 \mathrm{keV} / \mathrm{B}_{\mathrm{eq}}$
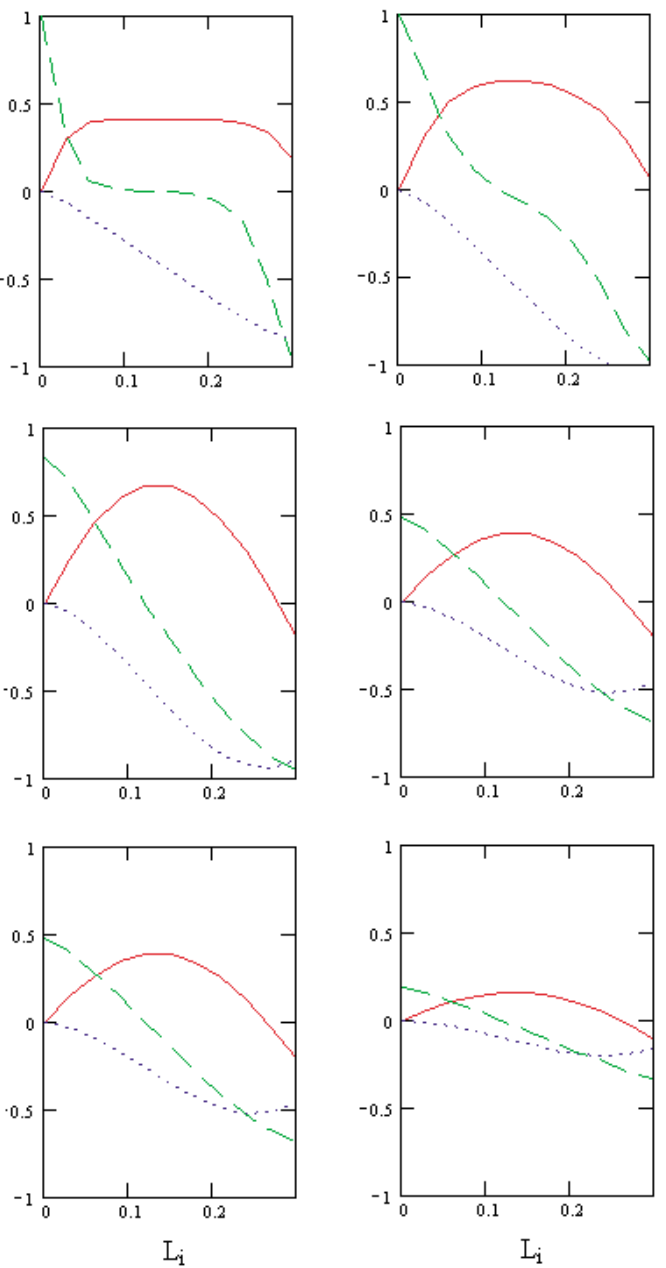
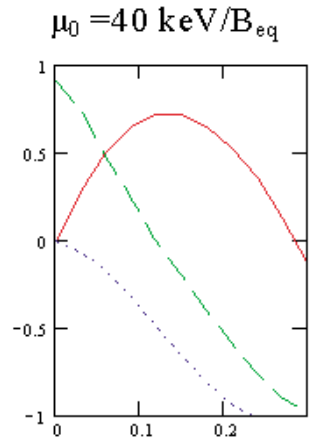

$\mathrm{j}=3$
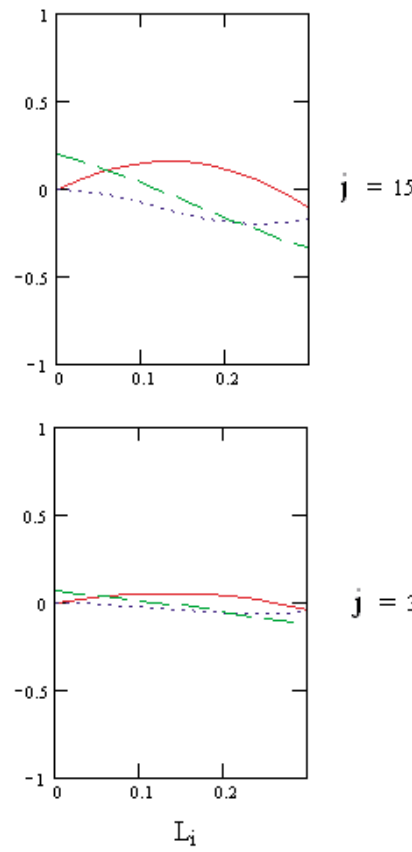

$\mathrm{j}=30$

Fig. 4. Modelled cross-PJ profiles of the normalized charge density $N_{r 0}$, electric field $E^{e q}$ and potential $U^{e q}$ for the distribution functions with $\mu_{0}=5,10,20$ and $40 \mathrm{keV} / B^{e q}$ (4 columns) at the times 18, 90 and 180 min after the start of the quasi-steady stage ( 3 rows).

profiles of $N_{r 0}(\ell), E^{e q}(\ell)$, and $U^{e q}(\ell)$ are shown for the four distribution functions and the three rows are for the times 18 , 90 and 180 min after the injection.

Several interesting features of the model profiles are worth mentioning:

(1) Self-consistency of the simplified model. For the two lower values of $\mu_{0}$ during about $90 \mathrm{~min}$, the assumption in this simplified model version that $E_{P J}^{e q}=$ const is in reasonable accord with the calculated cross-PJ potential differences. This duration is of the order of the observed PJ lifetime, though lower than average. However, the average value of $E_{P J}^{e q}$ and the potential drop $\Delta U^{e q}$ decrease more and more for higher energies and later times. Evidently, the nonlinear evolution of the band and particle motions in it are to be accounted for in the future development of the model.

(2) PJ lifetime. (a) It is seen that while for the particle distribution with small $\mu_{0}$, a quite significant PJ remains even $3 \mathrm{~h}$ after the injection, it nearly ceases by that time for the large $\mu_{0}$. These model results are in qualitative accord with the observed lifetime of the PJ. (b) The PJ lifetime after an injection due to this mechanism is of the order of the time $\tau_{p}$, as was expected from theoretical considerations. (c) The decrease in $E_{P J}^{e q}$ with time will increase the PJ lifetime in comparison with that calculated above.

(3) Latitude profiles. (a) The $E_{P J}^{e q}$ latitude profile, after a short initial period, has the bell shape. In the model it is due to the exponential form of the distribution function, and thus, is expected to be retained in the more elaborated future versions. This inference from the simplified model is in good accord with the observations (see, Rich et al., 1980). (b) As the azimuthal dependence of the particle entry through the equatorial and polar borders can be different, both in space and in time, the symmetrical development seen in the model is the result of the simplifying assumptions of the model. So, in this way, various scenarios of particle injection can be modelled 
with more realistic geometries and time evolution.

The aim of this schematic modelling, as mentioned above, was only to illustrate the idea of the dispersion mechanism of the PJ formation. A much more elaborated modelling is needed, taking into account nonlinear development in space and time of the particle entry, varying electric fields, currents and ionospheric conductivity. However, despite many simplifying assumptions, the model results presented show a reasonably good agreement with the observed gross characteristics of the PJ.

\section{The PJ formation stage}

The most difficult task is to assess and to model the initial, or the formation stage of the PJ. During an injection, an important and rapid time evolution of all the parameters, the magnetic and electric fields, particle spectra and intensities take place at the subauroral $L$-shells. We rely on the experimental and model results presented by Birn et al. (1997a, b; 1998) for the geostationary orbit, and the case study by Sergeev et al. (1998) from the CRRES. There is still no accepted physical model of the deep injection, while the above cited papers give important information for the analysis.

As was shown both by the ground-based measurements (Khalipov et al., 2001) and occasionally by satellite experiments (see, for example, the Fig. 9 from Karlsson et al., 1998), the formation of the PJ band near the region of the origin close to midnight can last less than $10 \mathrm{~min}$. Usually it follows an intense burst of $A E$-index which may be identified with the injection. In addition, the observations by Khalipov et al. (2001) at $L=3$ indicate that the PJ formation above a station is sometimes accompanied by a rapid westward passage of the Harang Discontinuity (HD). The time-dependent process of the strong electric field generation by the rapid charge accumulation deep in the subauroral magnetosphere at the edges of the PJ band is still poorly understood. Evidently, it can be modeled only by a rather elaborated dynamical model of the type used by Birn et al. (1997; 1998) which is out of the scope of this paper.

However, some crude estimates of the time scale of the formation process can be made here to check the consistency of the theory described above with the observations on the order of magnitude.

We suppose that the injection takes place near the HD (Erickson et al., 1991). At the eastward/equatorward tip of the HD before the injection, the equipotentials are aligned nearly along the meridian (see scheme in Fig. 1a). Here, the start of the charging after a local injection can be the most rapid, as the injected energetic ions drift westward at a large angle to the equipotentials of the westward electric field. Hence, the ions are displaced equatorward in their drift, so that the charging of the inner $L$-shells begins to accumulate.

The PJ formation time will also depend on the energy spectrum and mean energy of the injected particles (see Sect. 3). Further to the west from the tip of the HD, the drift length for an ion across the forming PJ band increases to $\ell_{m} \sim \operatorname{cosec} \alpha \cdot 100 \mathrm{~km}$, where the changing angle $\alpha$ is between the equipotentials and the $B^{e q}=$ const surfaces westward from the injection region. We assume for an estimate $\ell_{m} \sim 600 \mathrm{~km}$, which would be sufficient for the registration of the appearance of the PJ above a ground station. The magnetic gradient/curvature drift velocity projected onto ionosphere $V_{g r}^{i}$ for an energetic ion in the dipole magnetic field, neglecting betatron acceleration, can be estimated from

$V_{g r}^{i}=V_{g r}^{e q} L^{-3 / 2}=0.0152 \epsilon[\mathrm{keV}] \cdot L^{-1 / 2} \mathrm{~km} \mathrm{~s}^{-1}$.

At $L=4$, the PJ westward drift velocity $V_{C}^{i} \approx 1 \mathrm{~km} / \mathrm{s}$ corresponds to the gradient drift velocity of an injected ion of the "resonance" energy $\epsilon_{r}=32.8 \mathrm{keV}$. Let the westward electric field at the tip of the HD in the ionosphere during the early stage of the PJ development be $E_{W}^{i}=10 \mathrm{mV} / \mathrm{m}$, which corresponds to the electric drift velocity $0.2 \mathrm{~km} / \mathrm{s}-$ a modest value for the HD which is much lower than the minimal PJ velocity in a steady state. Then the total westward "resonance" ion velocity is $\sim 1.2 \mathrm{~km} / \mathrm{s}$ (it will increase during the drift due to the betatron acceleration, but slightly decrease due to a decrease in $L$ ). To cover $600 \mathrm{~km}$ along the PJ at the initial stage of the PJ formation for these ions will take less than $600 \mathrm{~km} / 1.2 \mathrm{~km} / \mathrm{s} \sim 8.3 \mathrm{~min}$. This estimate is consistent with the observed short PJ formation time.

Note that the increasing positive charging of the equatorial boundary of the PJ by the westward and equatorward drifting energetic ions will also move this boundary equatorward. With the assumed $E_{W}^{i}=10 \mathrm{mV} / \mathrm{m}$ along $600 \mathrm{~km}$, an injected energetic ion of $32.8 \mathrm{keV}$ will increase its energy by $6 \mathrm{keV}$ and will be displaced from the initial $L=4.0$ to $L=3.78$, according to Eqs (6) and (8). This displacement defines the resulting width of the developing PJ. The ionospheric projection of the band from $L=3.78$ to $L=4.0$ has the width of $106 \mathrm{~km}$, consistent with the PJ observations.

At the same time, the tip of the HD, and the respective ionospheric closure currents near the equatorial border of the HD, will move westward since the potential here becomes more positive. This extends westward the morning positive convection cell near its equatorial border, which will be manifested by the westward shift of the HD.

This qualitative scenario, which follows from the assumed model (but was not modeled in this report), is consistent with the observed rapid development of the PJ band above a ground-based station with a field-of-view of several hundred $\mathrm{km}$, and with the westward passage of the HD above the station.

Above, only the contribution from the injected ions was considered. Another, and nearly simultaneous contribution to the charging of the PJ band, as was shown before, could come from the eastward drifting trapped electrons. These energetic electrons, coming from the evening region of the Ring Current, can be a result of a previous injection, or be the normal outer belt population. With the inclined polar border of the PJ band, they will enter it in a wide range of MLT, and due to the combined dispersive gradient and convection drifts, will similarly lead to the charging, but in this case, a negative one. 
The negative charging of the polar edge of the PJ will move the equipotentials in the evening side equatorward. (Note that an equatorward displacement of the equipotentials is typical of the evening sector, as described by several activity-dependent convection models, see above). This evolution presumably lasts about $10 \mathrm{~min}$ or less, and constitutes the formation stage of the PJ. Then, according to the model results described above, once inclined to the lines $B^{e q}$ = const, the PJ band evolves to a quasi-steady state and approximately conserves its configuration during a considerable time $\tau_{P}$ if the supply of the driving energetic particles from both sides continues.

\section{Discussion and conclusions}

The formation and relatively long persistence of a PJ band is not a rare phenomenon in the subauroral zone. But it apparently does not occur in every substorm or deep particle injection. In particular, the expected close correlation between the PJ events and the "nose structures" is not always observed, despite their apparently similar origin.

This indicates that some additional factors influence the PJ formation in the shielding of the inner magnetosphere from the external (magnetospheric) electric field. These factors, as well as the physical processes of the "injection" in the inner magnetosphere, are still not fully clear. The structure of the "injection front" was recently documented and studied from the CRRES satellite by Sergeev et al. (1998). Its inward velocity was shown to be comparable to the convection speed and was accompanied by the betatron acceleration of particles; however, these features of the injection remain unexplained. These data, though unique, can be used as a test of various injection models that could or could not include the PJ formation. In particular, it would be interesting to apply the ideas on the rotational discontinuity described by De Keyser et al. (1998), and De Keyser (1999) for a quantitative description of the "injection front" observed from the CRRES satellite.

In this study, we do not consider these dynamic formation processes, but only make simple evaluations of their spatial extent and time duration near the equatorial boundary of the large-scale convection in the region of the Harang Discontinuity. While these evaluations appear to be generally consistent with the experimental data on the PJ formation, it is evident that the problem of injection in the inner magnetosphere needs further experimental studies, a detailed theoretical analysis and modelling. It is hoped that the semiquantitative estimates made above will not be inconsistent with these further developments of the problem.

The observed, quasi-steady location of the PJ events just at, or near, the plasmapause is one of the main problems for any PJ model. In this model, this property of the PJ comes quite naturally due to the following two factors. The first one is that the PJ develops inward from the large-scale convection boundary where the westward electric field is present at the time of the expansion phase and later. According to the avail-

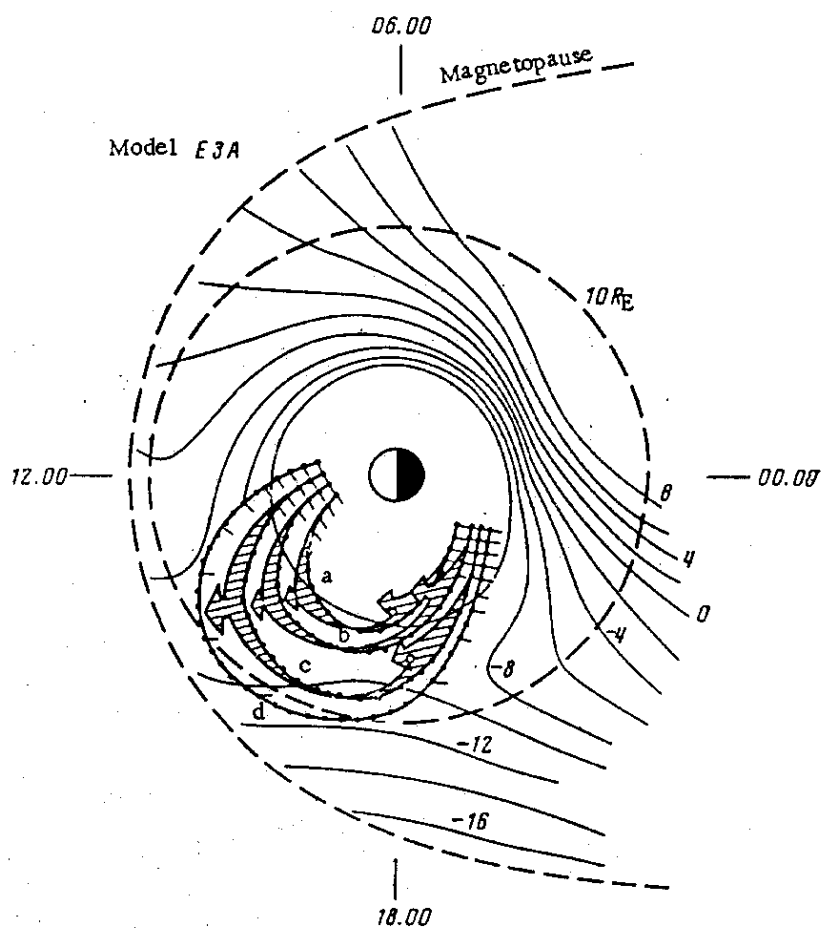

Fig. 5. Comparison of the driftmeter data from the low-altitude Kosmos-184 satellite with the model E3A (McIlwain, 1972 and personal communication, 1974) reproduced from Galperin et al. (1975; their Fig. 4). Thin curves are equipotential contours in the model (potential in $\mathrm{kV}$ ). The trajectories of the Kosmos-184 were projected onto the equatorial plane by means of the model by Fairfield, 1968. The measured convection flow velocity directions are shown both during disturbed conditions on passes (a) $118 \mathrm{~S}$; (b) $119 \mathrm{~S}$; and (c) $164 \mathrm{~S}$; and during extremely quiet conditions on the pass (d) $194 \mathrm{~S}$ when only corotation velocity was registered.

able data on the convection during disturbed conditions (see, for example, Vondrak and Rich, 1982; Sanchez at al., 1996), the electric field (convection) near its equatorial boundary in the evening and premidnight sectors is often directed mainly poleward (westward) with an inward drift velocity component. This indicates the presence of a westward electric field component which must lead to the inward drift of the injected energetic ions. The second factor is the absence of diffuse electron precipitation inward from the convection boundary, i.e. inside the plasmasphere. Hence, in the subauroral ionosphere, a much lower conductivity exists in the PJ band in the non-sunlit conditions or at a high solar zenith angle, which helps to keep high the cross-PJ electric field during energetic particles influx.

One of the aspects of the simplified model results shown above is the longer time duration of PJ events for lower energy injections than for higher energy ones - a natural consequence of the slower gradient/curvature drift for the former. Hence, the PJ induced by the former can last longer than that induced by the latter in case of an energetic ion injection, and thus, has a higher probability to be registered. So it is predicted by the model that the correlation between the 
PJ events and the "nose structure" events will be better for lower energy injections. We suppose this is a factor that deteriorates the correlation between the PJ and the high energy "nose structure" events. This assumption can be checked experimentally.

It is an example where the above described model may allow one to check experimentally some of the predicted observable features related to the PJ. Such features include the "nose structure" of energetic protons which appears after a deep particle injection, the intimately related SAR arc, the electron density inhomogenieties accompanying PJ, etc.

As follows from the calculations of the PJ quasi-steadystate described in Sect. 3, the equipotentials in the evening to midnight MLT sector are supposed to be inclined with respect to the lines $B^{e q}=$ const at some small but significant angle $\alpha_{0} \approx 0.1-1^{\circ}$. For this, during the substorm injection, they need to be moved inward in the evening MLT sector with respect to the midnight one. This is the main hypothesis of this theory.

This hypothesis seems consistent with the data on the plasma drifts in the evening sector during disturbed times, as was described in Galperin et al. (1975) from the Kosmos-184 measurements in November, 1967. The schematics of these measurements taken from the above paper (Fig. 4 there) are reproduced here as Fig. 5. In this figure, the plasma drift directions measured by the driftmeter along the respective orbits from the Kosmos-184 satellite were projected onto the equatorial plane. The orbits which reached the highest invariant latitudes (orbit $d$ in Fig. 5 on pass 194S and the next pass $195 \mathrm{~S}$ above the Southern Hemisphere) occurred during an extremely quiet time on 7 November 1967 (a QQ day with $\Sigma K_{p}=5+$ ). The drift data from these passes showed nearly corotating plasma up to invariant latitudes $70-71^{\circ}$ in the evening sector. However, the passes during disturbed times showed sunward flows at much lower invariant latitudes in accord with the McIlwain's model E3A (McIlwain, 1972), as seen in Fig. 5. Thus, a very significant inward displacement of the drift trajectories occurs during disturbances in the evening and midnight sectors. Such a "caving in" of the equipotentials in the evening sector during a disturbance can also be seen near the geostationary orbit (see, for example, Carpenter et al., 1992; 1993). It is also consistent with other activity-dependent empirical models of convection based on the satellite data by McIlwain (1986), Heppner and Maynard (1987), Hairston and Heelis (1990), Weimer (1996), as well as with the very successful Volland-Stern conceptual model (Volland, 1973; Stern, 1975).

The drift-dispersion mechanism of the PJ formation proposed here and the simplified model above prescribe the amount of "caving in" of the equipotentials with respect to the lines $B^{e q}=$ const in the evening sector as the small angle $\alpha$ between them needed for the PJ formation. The model shows its significant consequences for the energetic particle motion, and for the generation of the so-called shielding electric field. Indeed, in our model, the electric field intensity at the equatorial border of convection is much higher and more concentrated in latitude than according to the above men- tioned average convection models. In addition, this enhanced electric field evolves quickly after an injection, so that the field, initially westward, turns to the radial (poleward) direction. Thus, in fact, it is a manifestation of the shielding process that reduces the external electric field penetration deep in the inner magnetosphere which was considered by many authors (see, for example, Jaggi and Wolf, 1973; Gurevich et al., 1976).

To summarize, the model described above proposes a simple scheme - the inward displacement of the equipotentials in the evening and premidnight sector, and the resulting inclination of the equipotentials with respect to the lines $B^{e q}=$ const in the equatorial plane. Within this model, semiquantitative estimates were made of the observable characteristics of the PJ events:

- formation time of the PJ ( 5-10 min);

- accompanying westward displacement of the Harang Discontinuity near the injection meridian by several hundred km;

- resulting enhanced electric field at the equatorial PJ projection $(\sim 5-10 \mathrm{mV} / \mathrm{m})$ and total potential difference across the band $(\sim 10 \mathrm{kV})$;

- bell-shape of the latitudinal electric field profile in the quasi-steady stage;

- Pedersen conductivity $(\sim 0.1 \mathrm{~S})$ in the underlying subauroral ionosphere;

- linear Pedersen current density $\left(\sim 10^{-2} \mathrm{~A} / \mathrm{m}\right)$ across the $\mathrm{PJ}$ band in the two-sheet Birkeland current loop;

- lifetime of the PJ quasi-steady stage $(\sim 1-3 \mathrm{~h})$;

- $\Lambda_{0}$-MLT location and extent of the PJ band in the nightside-evening sectors.

All these model results and semi-quantitative estimates of currents, ionospheric conductivity and cross-PJ potential drop are in rough accord with the observed typical characteristics for the PJ events.

The model assumes the charge accumulation in the magnetosphere and discharge processes through the conducting ionosphere in an extremely simplified scheme, neglecting the nonlinearity and complicated time development. These aspects of the model, as well as the relation between the PJ and the "nose structure", are under analysis and are deferred to later publications.

As is known, the downward current carried by the upward moving cold ionospheric electrons, and closed by the cross-PJ Pedersen current, can neutralize the positive charges at the equator without a significant potential difference involved for low current densities. But if the scattering of hot electrons of the inner plasma sheet/diffuse auroral zone into the loss cone is not sufficient to carry the upward current, the ionospheric ions must be accelerated upward against the gravitational force to neutralize the negative charges at the 
equator. Then a small upward directed electric field capable of sustaining the upward current could be expected in such a scenario at the polar edge of the PJ band. Its magnitude will depend on the location of this border with respect to the equatorial boundary of hot electrons, on their energy and pitch-angle scattering rate there. A related heating of ionospheric electrons and a weak SAR arc formation (see, for example, observations by Foster et al., 1994) is also expected in this scenario. It will be a direct consequence of the field-aligned currents, and of an enhanced collisional heating, together with exothermal chemical reactions in the ionosphere, leading to the increase of the effective recombination coefficient due to fast ion drift with respect to neutrals. These details need thorough modelling in order to become quantitative, but qualitatively, they are consistent with the available data and the model presented.

Evidently, a much more elaborate theory and modelling is needed for a comprehensive description of the particle injection phenomena in the inner magnetosphere during disturbed times, probably among the ways described by Gurevich et al. (1976).

Acknowledgement. I am grateful to my colleagues, especially to N. Yu. Buzulukova, for discussions of the various aspects of this problem, and help in the model calculations. Special thanks are to the Referee 1 (J. De Keyser) for constructive and helpful comments. This work was supported partly by the grant JURRISS NAG5-8638 from NASA, and by the INTAS grant 2000-465.

Topical Editor G. Chanteur thanks J. de Keyser for his help in evaluating this paper.

\section{References}

Alexeev, V. N., Ievenko, I. B., Yugov, V. A., Ignatyev, V. M., and Khalipov, V. L.: Complex photometric, interpherometric and ionospheric measurements in the SAR-arc observation region, Geomagn. and Aeronomy (English translation), 34, 63-68, 1994.

Anderson, P. C., Hanson, W. B., and Heelis, R. A.: The ionospheric signatures of rapid subauroral ion drifts, J. Geophys. Res., 96, 5785-5792, 1991.

Anderson, P. C., Hanson, W. B., Heelis, R. A., Craven, J. D., Baker, D. N., and Frank, L. A.: A proposed production model of rapid subauroral ion drifts and their relationship to substorm evolution, J. Geophys. Res., 98, 6069-6078, 1993.

Bankov, L. G., Stanev, G. A., Vassileva, A. K., Kirova, V. A., Danov, D. L., Hanson, W. B., Heelis, R. A., and Anderson, P. C.: A case study of Subauroral Ion Drift velocity jets by means of Dynamics Explorer-2 and Intercosmos Bulgaria-1300 satellites data, Adv. Space Res., 17, 10, 10, 193-200, 1996.

Banks, P. M. and Yasuhara, F.: Electric Fields and Conductivity in the Nighttime F-Region: A New Magnetosphere-IonosphereAtmosphere Coupling Effect, Geophys. Res. Lett., 5, 12, 10471050, 1978.

Birn, J., Thomsen, M. F., Borovsky, J. E., Reeves, G. D., McComas, D. J., and Belian, R. D.: Characteristic plasma properties of dispersionless substorm injections at geosynchronous orbit, J. Geophys. Res., 102, 2309-2324, 1997a.

Birn, J., Thomsen, M. F., Borovsky, J. E., Reeves, G. D., McComas, D. J., Belian, R. D., and Hesse, M.: Substorm ion injections:
Geosynchronous observations and test particle orbits in threedimensional dynamic MHD fields, J. Geophys. Res., 102, 2325, 1997b.

Birn, J., Thomsen, M. F., Borovsky, J. E., Reeves, G. D., McComas, D. J., Belian, R. D., and Hesse, M.: Substorm electron injections: Geosynchronous observations and test particle simulations, J. Geophys. Res., 103, 9235-9248, 1998.

Burke, W. J., Maynard, N. C., Hagan, M. P., Wolf, R. A., Wilson, G. R., Gentile, L. C., Gussenhoven, M. S., Huang, C. Y., Garner, T. W., and Rich, F. J.: Electrodynamics of the inner magnetosphere observed in the dusk sector by CRRES and DMSP during the magnetic storm of June 4 - 6 1991, J. Geophys. Res., 103, 29399-29418, 1998.

Burke, W. J., Rubin, A. G., Maynard, N. C., Gentile, L. C., Sultan, P. J., Rich, F.J., de la Beaujardiere, O., Huang, C. Y., and Wilson, G. R.: Ionospheric disturbances observed by DMSP at middle to low-latitudes during magnetic storm of June 4-6, 1991, J. Geophys. Res., 105, 18 391-18 405, 2000.

Carpenter, D. L., Giles, B. L., Chappell, C. R., Decreau, P. M. E., Anderson, R. R., Persoon, A. M., Smith, A. J., Corcuff, Y., and Canu, P.: Plasmasphere dynamics in the duskside bulge region: A new look at an old topic, J. Geophys. Res., 98, 19243-19271, 1993.

Carpenter, D. L., Smith, A. J., Giles, B. L., Chappell, C. R., and Décreau, P. M. E.: A case study of plasma structure in the dusk sector associated with enhanced magnetospheric convection, J. Geophys. Res., 97, 1157-1166, 1992.

Chen, A. J.: Penetration of low-energy protons deep into the magnetosphere, J. Geophys. Res., 75, 2458-2467, 1970.

De Keyser, J.: Formation and evolution of subauroral ion drifts in the course of a substorm, J. Geophys. Res., 104, 12 339-12 349, 1999.

De Keyser, J., Roth, M., and Lemaire, J.: The magnetospheric driver of subauroral ion drifts, Geophys. Res. Lett., 25, 1625-1628, 1998.

Deminov, M. G. and Shubin, V. N.: Dynamics of nightside subauroral F-region during disturbed conditions, Geomagn. and Aeron.(in Russian), 27, 398-403, 1987.

Deminov, M. G. and Shubin, V. N.: Electric field effects in the night-side subauroral F-region, Geomagn. and Aeron.(in Russian), 28, 409-415, 1988.

Ejiri, M., Hoffman, R. A., and Smith, P. H.: Energetic particle penetrations into the inner magnetosphere, J. Geophys. Res., 85, 653$663,1980$.

Erickson, G. M., Spiro, R. W., and Wolf, R. A.: The physics of the Harang discontinuity, J. Geophys. Res., 96, 1633-1645, 1991.

Filippov, V. M., Reshetnikov, D. D., Khalipov, V. L., Soloviev, V. S., Stepanov, A. E., Galperin, Y. I., and Mularchik, T. M.: Complex measurements of narrow ionisation throughs in the F-region by ground-based and satellite methods, Cosmic Research (in Russian), 27, 568-584, 1989.

Fontaine, D. and Peynriat, C.: Large-scale distributions of ionospheric horizontal and field-aligned event from EISCAT, Ann. Geophysicae, 14, 1284-1296, 1996

Foster, J. C., Buonsanto, M. J., Mendillo, M., Nottingam, D., Rich, F. J., and Denig, W.: Coordinated stable auroral red arc observations: Relationship to plasma convection, J. Geophys. Res., 99, 11429-11 439, 1994.

Galperin, Y. I., Khalipov, V. L., and Filippov, V. M., Signature of rapid subauroral ion drifts in the high-latitude ionosphere structure, Ann. Geophys., 4, 145-154, 1986.

Galperin, Y. I., Ponomarev, V. N., and Zosimova, A. G.: Direct mea- 
surements of ion drift velocity in the upper ionosphere during a magnetic storm, 2. Results of measurements during the November 3, 1967, magnetic storm, Cosmic Research (in Russian), 11, 283-292, 1973

Galperin, Y. I., Ponomarev, V. N., and Zosimova, A. G.: Plasma convection in the polar ionosphere, Ann. Geophysicae, 30, 1-7, 1974.

Galperin, Y. I., Ponomarev, V. N., Ponomarev, Y. N., and Zosimova, A. G.: Plasma convection in the evening sector of the magnetosphere and the nature of the plasmapause, Cosmic Research (in Russian), 13, 669-686, 1975.

Ganushkina, N. Y., Pulkkinen, T. I., Sergeev, V. A., Kubyshkina, M. V., Baker, D. N., Turner, N. E., Grande, M., Kellett, B., Fennell, J. F., Roeder, J. L., Sauvaud, J.-A., and Fritz, T. A.: Entry of plasma sheet particles into the inner magnetosphere as observed by Polar/CAMMICE, J. Geophys. Res., 105, 25205 $25219,2000$.

Grigoriev, S. A., Zinin, L. V., Vasilenko, I. Yu., and Lynovsky, V. E.: Multi-ion one-dimensional MHD models for dynamics of the high-latitude ionosphere. 1. Mathematical model of ionosphere with account of seven positive ion species, Cosmic Research (in Russian), 37, 451-462, 1999.

Gurevich, A. V., Krylov, A. L., and Tsedilina, E. E.: Electric fields in the Earth's magnetosphere and ionosphere, Space Sci. Rev., 19, 59-160, 1976.

Hairston, M. R. and Heelis, R. A.: Model of high-latitude ionospheric convection pattern during southward interplanetary magnetic field using DE 2 data, J. Geophys. Res., 95, 2333-2343, 1990.

Heppner, J. P. and Maynard, N. C.: Empirical high-latitude electric field models, J. Geophys. Res., 92, 4467-4489, 1987.

Ievenko, I. B.: Dynamics of diffuse auroral emission and SAR-arc during substorm period, Cosmic Research (in Russian), 33, 4257, 1993.

Jaggi, R. K. and Wolf, R. A.: Self-consistent calculation of the motion of a sheet of ions in the magnetosphere, J. Geophys. Res., $78,2852,1973$

Karlsson, T., Marklund, G., Blomberg, L. G., and Malkki, A.: Subauroral electric fields observed by the Freja satellite: A statistical study, J. Geophys. Res., 103, 4327-4341, 1998.

Kaye, S. M. and Kivelson, M. G.: The influence of geomagnetic activity on the radial variation of the magnetospheric electric field between $L=4$ and 10, J. Geophys. Res., 86, 863-867, 1981.

Khalipov, V. L., Galperin, Y. I., Stepanov, A. E., and Shestakova, L. V.: Formation of the Polarisation Jet during substorm expansion phase: Results of ground-based measurements, Cosmic Res., 39, (submitted, 2000), 2001.

Konradi, A., Semar, C. L., and Fritz, T. A.: Substorm-injected protons and electrons and the injection boundary model, J. Geophys. Res., 80, 543-552, 1975.

Korosmezey, A., Rasmussen, C. E., Gombosi, T. I., and Khazanov, G. V.: Anisotropic ion heating and parallel O+ acceleration in regions of rapid $\boldsymbol{E} \times \boldsymbol{B}$ convection, Geophys. Res. Lett., 19, 22892292, 1992.

Lemaire, J. and Gringauz, K. I.: The Earth's Plasmasphere, Cambridge University Press, Cambridge, 1998.

Maynard, N. C., Aggson, T. L., and Heppner, J. P.: Magnetospheric observation of large subauroral electric fields, Geophys. Res. Lett., 7, 881-884, 1980.

McIlwain, C. E.: A $K_{p}$-dependent equatorial electric field model, Adv. Space Res., 6, 3, 187-197, 1986.

McIlwain, C. E.: Plasma convection in the vicinity of the geosyn- chronous orbit, in: Earth's Magnetospheric Processes, (Ed) McCormac, B. M., D. Reidel Pub. Co., Dordrecht-Holland, 268279, 1972.

Moffett, R. J., Ennis, A. E., Bailey, G. J., et al.: Electron temperature during rapid subauroral ion drift events, Ann. Geophysicae, 16, 450-459, 1998.

Nopper, R. W. and Carovillano, R. L.: Polar-equatorial coupling during magnetically active periods, Geophys. Res. Lett., 5, 699$702,1978$.

Ober, D. M., Horwitz, J. L., and Gallagher, D. L.: Formation of density troughs embedded in the outer plasmasphere by subauroral ion drift events, J. Geophys. Res., 102, 14 595-14 602, 1997.

Providakes, J. F., Kelley, M. C., Swartz, W. E., Mendillo, M. and Holt, J. M.: Radar and optical measurements of ionospheric processes associated with intense subauroral electric fields, J. Geophys. Res., 94, 5350-5366, 1989.

Rich, F. J., Burke, W. J., Kelley, M. C., and Smiddy, M.: Observations of field-aligned currents in association with strong convection electric fields at subauroral latitudes, J. Geophys. Res., 85 2335-2340, 1980.

Rodger, A. S., Moffett, R. J., and Quegan, S.: The role of the ion drift in the formation of ionisation troughs in the mid- and highlatitude ionosphere - A review, J. Atmos. Terr. Phys., 54, 1-30, 1992.

Rowland, D. and Wygant, J.: Dependence of the large-scale, inner magnetospheric electric field on geomagnetic activity, J. Geophys. Res., 103, 14 959-14 964, 1998.

Sanchez, E. R., Ruohoniemi, J. M., Meng, C.-I., and FriisChristensen, E.: Toward an observational synthesis of substorm models: Precipitation regions and high-latitude convection reversals observed in the nightside auroral oval by DMSP satellites and HF radars, J. Geophys. Res., 101, 19 801-19 837, 1996.

Sergeev, V. A., Shukhtina, M. A., Rasinkangas, R., Korth, A., Reeves, G. D., Singer, H. J., Thomsen, M. F., and Vagina, L. I.: Event study of deep energetic particle injections during substorm, J. Geophys. Res., 103, 9217-9234, 1998.

Sivtseva, L. D ., Filippov, V. M., Khalipov, V. L., Galperin, Y. I., Ershova, V. A., Nikolaenko, L. M., Ponomarev, Y. N., and Sinitsin, V. M.: Coordinated investigations of processes in the subauroral upper ionosphere and the light-ion concentration trough, Cosmic Research (in Russian), 22, 720-741, 1984.

Smiddy, M., Kelley, M. C., Burke, W. J., Rich, F. J., Sagalyn, E., Shuman, B., Hays, R., and Lai, S.: Intense poleward directed electric fields near the ionospheric projection of the plasmapause, Geophys. Res. Lett., 4, 11, 543-546, 1977.

Southwood, D. J. and Wolf, R. A.: An assessment of the role of precipitation in magnetospheric convection, J. Geophys. Res., 83, A11, 5227-5232, 1978 .

Spiro, R. W., Harel, M., Wolf, R. A., and Reiff, P. H.: Quantitative simulation of a magnetospheric substorm. 3. Plasmaspheric electric fields and evolution of the plasmasphere, J. Geophys. Res., 86, 2261-2272, 1981

Spiro, R. W., Heelis, R. A., and Hanson, W. B.: Rapid subauroral ion drifts observed by Atmospheric Explorer C, Geophys. Res. Lett., 6, 660-663, 1979.

Stern, D. P.: The motion of a proton in the equatorial magnetosphere, J. Geophys. Res., 80, 4, 595-599, 1975

Unwin, R. S. and Cummack, C. H.: Drift spikes: The ionospheric signature of large poleward directed electric fields at subauroral latitudes, Mem. Nat. Inst. Polar Res., 16 (Special Issue "IMS in Antarctica"), 72-83, 1980.

Volland, H.: A semiempirical model of the large-scale magneto- 
spheric electric fields, J. Geophys. Res., 78, 171-180, 1973.

Vondrak, R. R. and Rich, F. J.: Simultaneous Chatanika radar and S3-2 satellite measurements of ionospheric electrodynamics in the diffuse aurora, J. Geophys. Res., 87, 6173-6185, 1982.

Weimer, D. R.: A flexible, IMF-dependent model of high-latitude electric potentials having "space weather" applications, Geophys. Res. Lett., 23, 2549-2552, 1996.

Wygant, J., Rowland, D., Singer, H. J., Temerin, M., Mozer, F. S., and Hudson, M. K.: Experimental evidence on the role of the large spatial scale electric field in creating the ring current, J. Geophys. Res., 103, 29 527-29 544, 1998.

Yeh, H.-C., Foster, J. C., Rich, F. J., and Swider, W.: Storm time electric field penetration observed at mid-latitude, J. Geophys. Res., 96, 5707-5721, 1991.

Zinin, L. V., Galperin, Y. I., Grigoriev, S. A., and Mularchik, T. M.: On measurements of the Polarization Jet effects in the outer plasmasphere, Cosmic Research (English version), 36, 39-48, 1998. 